Provided for non-commercial research and education use. Not for reproduction, distribution or commercial use.

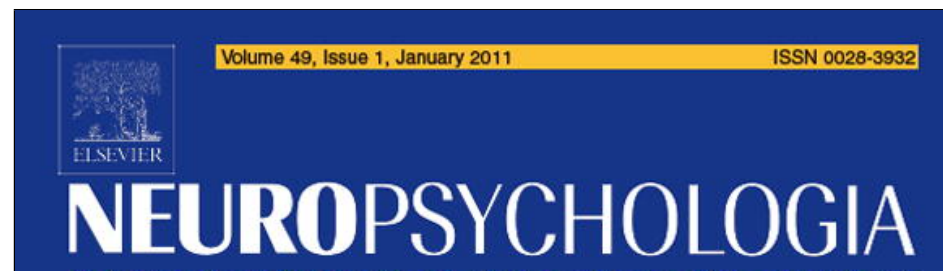

An international iournal in behovioural and cognitive neuresciener

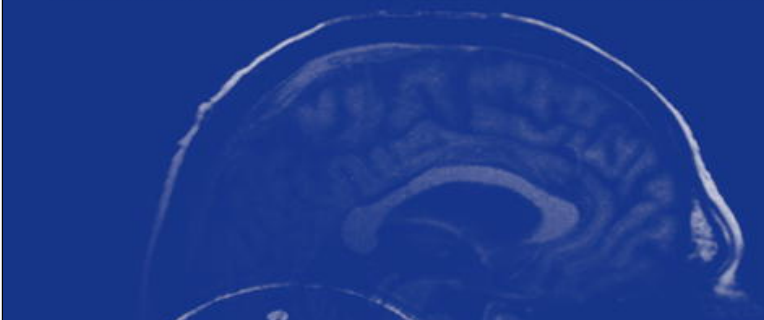

This article appeared in a journal published by Elsevier. The attached copy is furnished to the author for internal non-commercial research and education use, including for instruction at the authors institution and sharing with colleagues.

Other uses, including reproduction and distribution, or selling or licensing copies, or posting to personal, institutional or third party websites are prohibited.

In most cases authors are permitted to post their version of the article (e.g. in Word or Tex form) to their personal website or institutional repository. Authors requiring further information regarding Elsevier's archiving and manuscript policies are encouraged to visit:

http://www.elsevier.com/copyright 


\title{
Correlated deficits of perception and action in optic ataxia
}

\author{
R.D. McIntosh ${ }^{\mathrm{a}, *}$, A. Mulroue $^{\mathrm{a}}$, A. Blangero $^{\mathrm{b}}$, L. Pisella $^{\mathrm{c}}$, Y. Rossetti $^{\mathrm{c}, \mathrm{d}}$ \\ a Human Cognitive Neuroscience, University of Edinburgh, 7 George Square, Edinburgh, UK \\ ${ }^{\mathrm{b}}$ Department of Biology, City College of New York, 160 Convent Avenue, New York 10031, USA \\ ${ }^{\mathrm{c}}$ Espace et Action (IMPACT), INSERM UMR-S 864 E'Université de Lyon, Centre des Neurosciences de Lyon, 16 Avenue Lépine, 69676 Bron, France \\ ${ }^{\mathrm{d}}$ Mouvement et Handicap, Hôpital Henry Gabrielle, Hospices Civils de Lyon, Inserm et Université de Lyon, Route de Vourles, 69230 St. Genis Laval, France
}

\section{A R T I C L E I N F O}

Article history:

Received 11 August 2010

Received in revised form 27 October 2010

Accepted 12 November 2010

Available online 19 November 2010

\section{Keywords:}

Action

Attention

Perception

Vision

Visuomotor

\begin{abstract}
A B S T R A C T
Optic ataxia, following dorsal stream lesions, is characterised by impaired visuomotor guidance. Recent studies have found concurrent perceptual deficits, but it is unclear whether these are functionally related to the visuomotor symptoms. We studied the ability of a well-documented patient(IG) with bilateral optic ataxia to react to sudden target jumps by correcting ongoing reaches or by explicitly reporting the jump direction. IG showed deficient reach corrections, especially for target jumps to the visual periphery, and was similarly slow to discriminate the same jumps perceptually. Across six test conditions, in which the retinal locations of target jumps were varied, her perceptual slowing mirrored her reaching deficit precisely. These findings confirm perceptual impairments after dorsal stream lesions, and imply a shared functional basis with the classical visuomotor symptoms of optic ataxia. Additionally, we show that the online correction deficit is determined dually by the retinal location to which the reach must be diverted, and the location to which it is initially directed. We suggest that this deficit, and its perceptual counterpart, can be traced to a slowed contralesional orienting of attention in optic ataxia.
\end{abstract}

(C) 2010 Elsevier Ltd. All rights reserved.

\section{Introduction}

The classical consequence of damage to the dorsal stream of vision in humans is optic ataxia, a disorder of visually-guided action (McIntosh, 2010; Pisella, Ota, Vighetto, \& Rossetti, 2008). Originally described amongst a cluster of symptoms following bilateral parietal lesions (Bálint, 1909), optic ataxia has been spotlighted in recent years, as central to understanding dorsal stream function (Goodale \& Milner, 1992; Milner \& Goodale, 2006; Pisella, Binkofski, Lasek, Toni, \& Rossetti, 2006; Rossetti, Pisella, \& Vighetto, 2003). The disorder is most evident following bilateral damage, but can also follow unilateral lesions, manifesting as misreaching within the contralesional visual field ('field effect') and/or with the contralesional hand ('hand effect') (Perenin \& Vighetto, 1988). Optic ataxia also compromises visuomotor sensitivity to non-target objects in the workspace. Normal people plan their reaches to steer a safe course between flanking obstacles, but two patients with bilateral optic ataxia (AT and IG) made no such adjustments (Schindler, Rice, McIntosh, Rossetti, \& Milner, 2004). Moreover, patients show deficient online control, failing to make fast corrections if the target of a reaching movement is unexpectedly displaced (Blangero et al., 2008; Gréa et al., 2002; Pisella et al., 2000). A recent study showed

\footnotetext{
* Corresponding author. Tel.: +44 131 6503444; fax: +44 1316503461.

E-mail address: r.d.mcintosh@ed.ac.uk (R.D. McIntosh).
}

a similar slowness to initiate corrective saccades to acquire displaced targets in a double-step eye movement task (Gaveau et al., 2008).

One key characteristic of optic ataxia is its dependence on retinal eccentricity. At least post-acutely, patients reach accurately to fixated targets, but accuracy declines dramatically with eccentricity (Blangero, Ota et al., 2010; Perenin \& Vighetto, 1988). It has been argued that this extrafoveal dependence is so fundamental that the definition of optic ataxia should exclude reaching errors in central vision (Jackson et al., 2009; Pisella et al., 2007, 2008, 2009). Consistent with this, the area of maximum lesion overlap in optic ataxia lies close to the parieto-occipital junction (POJ) (Blangero et al., 2009; Karnath \& Perenin, 2005), which, in healthy people, is differentially active during reaching to extrafoveal targets (Prado et al., 2005). Notably, Schindler et al.'s (2004) demonstration of impaired obstacle avoidance in optic ataxia used central fixation, with the obstacles lateralised to extrafoveal vision. Similarly, deficient online correction has been found for double-step reaching tasks in which the target jumps from central vision to an ataxic field (Blangero et al., 2008; Gréa et al., 2002; Pisella et al., 2000), but not for a grasping task in which a foveated target object undergoes an unexpected size change (Himmelbach, Karnath, Perenin, Franz, \& Stockmeier, 2006). It is thus possible that the various visuomotor symptoms of optic ataxia could all stem from an impaired ability to use extrafoveal visual information to drive immediate action.Traditionally, the clinical diagnosis of optic ataxia requires 
that perceptual deficits be excluded as an explanation for misreaching. However, this has usually been done quite coarsely, for instance by checking that objects within the ataxic field can be named (e.g. Garcin, Rondot, \& de Recondo, 1967). Recently, more stringent assessments have revealed impaired discrimination of object location or orientation in extrafoveal vision (Michel \& Henaff, 2004; Perenin \& Vighetto, 1988; Pisella et al., 2009; Rossetti et al., 2005). These perceptual impairments may reflect a reduced capacity to orient attention within, or towards the ataxic field (Blangero, Khan et al., 2010; Michel \& Henaff, 2004; Pisella et al., 2009). Indeed, Striemer et al. (2007) demonstrated impaired covert orienting of visual attention in two patients with unilateral optic ataxia, with slowed target detection for the ataxic field. A subsequent investigation with one of these patients addressed the key question of whether the perceptual problem was related to the misreaching, by comparing detection latencies and pointing accuracies across various retinal eccentricities (Striemer et al., 2009). Both measures were abnormal for the ataxic field, but only pointing accuracy was modulated strongly by eccentricity. Given this divergence, Striemer and colleagues suggested that the concurrent perceptual and visuomotor symptoms were functionally independent of one another. Their conclusion was tentative, however, especially given the very different indices of perceptual and visuomotor performance (detection latency vs. spatial accuracy). The possibility of perceptual counterparts for the visuomotor symptoms of optic ataxia remains very much open.

The first purpose of the present study is to re-examine the perceptual and visuomotor abilities of an extensively studied patient (IG) with bilateral optic ataxia. Pisella et al. (2000) previously found that IG was unable to make rapid corrections to her reaches in response to displacements of the target in a double-step reaching task. Crucially, when the task instruction was changed, IG could voluntarily stop her movement in response to the target jump as rapidly as controls. This allowed the authors to infer that the deficit of online correction was not related to any perceptual deficit. However, the result is actually ambiguous, because the voluntary (stop) response could have been made to the offset of the original target, whilst online correction requires processing of the new target location. Moreover, in a subsequent study, in which target location was changed during a memory delay, IG not only showed a visuomotor deficit, but also was unable to judge accurately whether the target had moved or not (Rossetti et al., 2005). This perceptual insensitivity to target displacements across a memory delay suggests that her immediate perceptual discrimination of target jumps may be worth re-evaluating.

To more definitively test for a perceptual counterpart to IG's online deficit, we used a better-matched perceptual control task, requiring the discrimination of jump direction. Like Striemer et al. (2009), we were interested in studying how perceptual and visuomotor performance change with the retinal location of the targets, so we systematically manipulated the locations of the initial target and the jumped target. A further purpose of this manipulation is that it allows us to explore the role of retinal position in determining the online deficit. All previous double-step studies in optic ataxia have presented the initial target in central vision, and jumped it to an extrafoveal location (Blangero et al., 2008; Gréa et al., 2002; Pisella et al., 2000). These studies have established that patients have difficulty correcting towards ataxic fields. The jumped target location is thus important, but it is unclear whether the initial target location also matters, since this has never been varied. One attractively simple hypothesis would be that the online correction deficit in optic ataxia depends solely upon the location towards which the reach must be diverted. This idea predicts impaired correction if the target of an ongoing reach jumps to an ataxic visual field, but rapid correction towards non-ataxic locations, such as central vision.

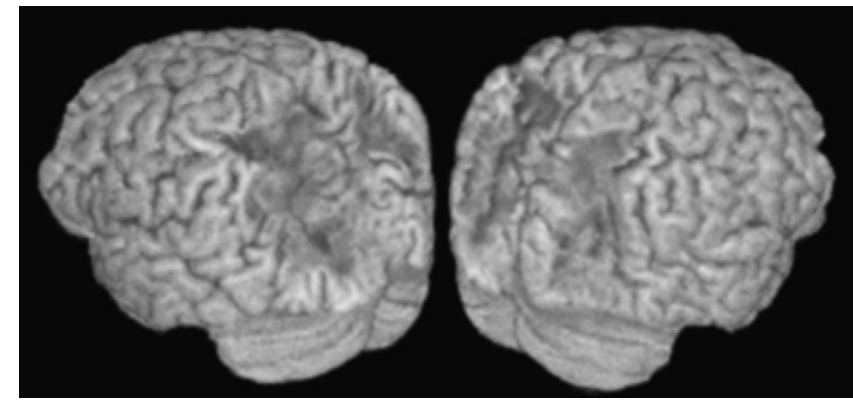

Fig. 1. A 3D reconstruction of IG's brain, visualized with structural MRI. Extensive damage is present bilaterally in the posterior parietal lobes.

\section{Methods}

\subsection{Participants}

Patient IG was a 40 year-old right-handed woman with bilateral parietooccipital infarcts following an ischaemic stroke 8 years previously. MRI revealed a hyperintense signal on T2 sequences that was near-symmetrically located in the posterior parietal and upper and lateral occipital cortico-subcortical regions (Fig. 1). Reconstruction of the lesion indicated that it involved mainly Brodmann's areas 7 , 18,19 , the intraparietal sulcus, and part of area 39 . She showed bilateral optic ataxia, misreaching for visual targets in extrafoveal vision, using either hand. Initially, she had also shown simultanagnosia on standard clinical tests (e.g. overlapping figures tests, verbal description of complex scenes, non-lateralised extinction), but this had resolved long before the present experiment (Pisella et al., 2000). Eleven righthanded healthy controls were also tested ( 8 females, 3 males; aged 25-52 years, mean 35.1, SD 9.2).

\subsection{Procedure}

The participant sat in darkness, $420 \mathrm{~mm}$ in front of a $21^{\prime \prime}$ CRT monitor (refresh rate $60 \mathrm{~Hz}$ ), with head immobilised in a chin-rest. Throughout each trial, the participant fixated a $6 \mathrm{~mm}\left(0.8^{\circ}\right.$ visual angle) grey cross, at the screen centre or $65 \mathrm{~mm}$ (8.8 visual angle) to the left or right.

\subsection{Reaching task}

In the reaching task, the participant depressed a button in front of them, with their right index finger, and a $12.5 \mathrm{~mm}$ ( $1.7^{\circ}$ visual angle) white dot (target 1$)$ appeared at the screen centre. The participant initiated a $500 \mathrm{~mm}$ forwards-andupwards reach towards it. Button release triggered the replacement of target 1 by target 2 , which was identical to target 1 , and located centrally (static trials) or $65 \mathrm{~mm}$ to the left or right (jump trials). A pacing beep, $300 \mathrm{~ms}$ after button release, encouraged IG to make fast movements. Her median movement time, on static trials, was $430 \mathrm{~ms}$; for controls, the pacing interval was set to $450 \mathrm{~ms}$, to encourage similar movement times. There were six blocks of 60 trials per block (40 static, 10 jump left, 10 jump right, pseudo-randomly ordered). Fixation was blocked (mid, left, right, right, left, mid).

\subsection{Perceptual discrimination task}

The discrimination task was performed after the reaching task, with an identical set-up, except that the right and left index fingers rested lightly on the right and left buttons of the response box respectively. The experimenter initiated onset of target 1 , which was replaced by target 2 after $500 \mathrm{~ms}$. The participant discriminated the direction of target jumps by pressing the corresponding button as soon as possible, withholding responses on static trials. Trials were ended by the response, or timed out after $2000 \mathrm{~ms}$. There were six blocks of 45 trials ( 15 static, 15 jump left, 15 jump right, pseudo-randomly ordered). Fixation was blocked (mid, left, right, right, left, mid).

\subsection{Data recording}

Stimulus control and button response recording were performed by a Cambridge Research Systems Visual Stimulus Generator. Eye-movements were recorded via a Cambridge Research Systems Video Eyetracker $(250 \mathrm{~Hz})$. Reaching responses were recorded via an Optotrak $3020^{\mathrm{TM}}$ system (Northern Digital Inc.), which sampled the 3D position of an infrared emitting diode, attached to the nail of the right index finger, at $200 \mathrm{~Hz}$. 
Fixate left
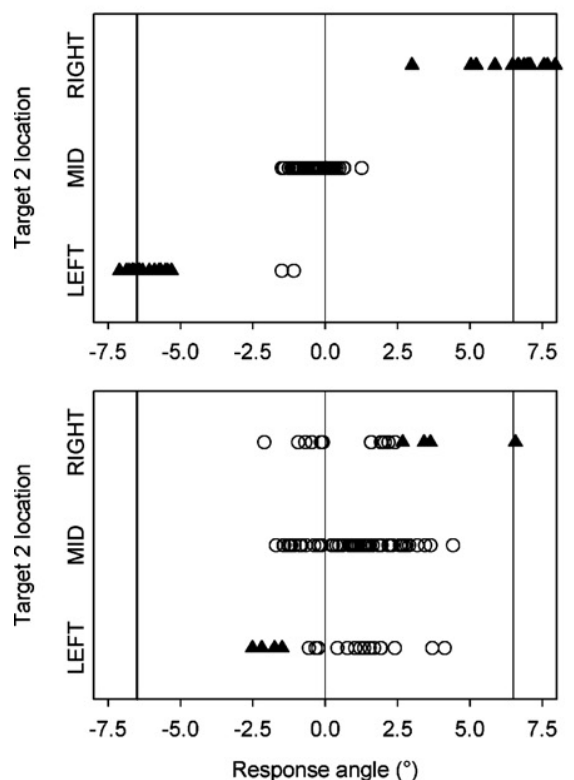

Fixate mid
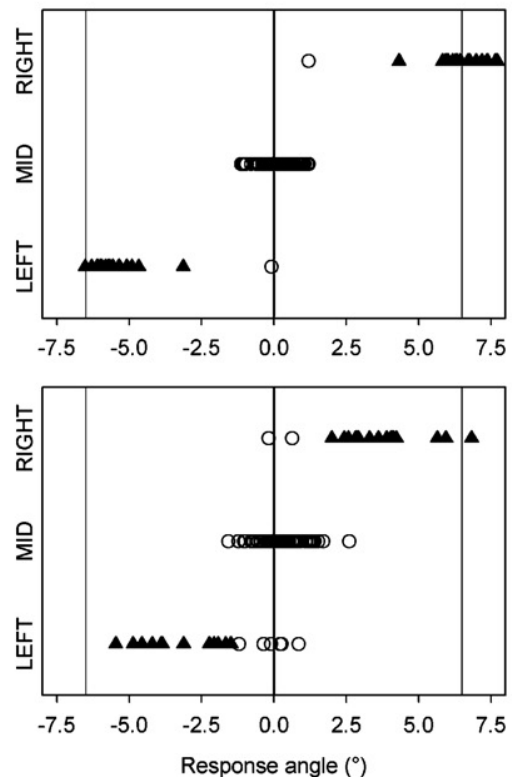

Fixate right
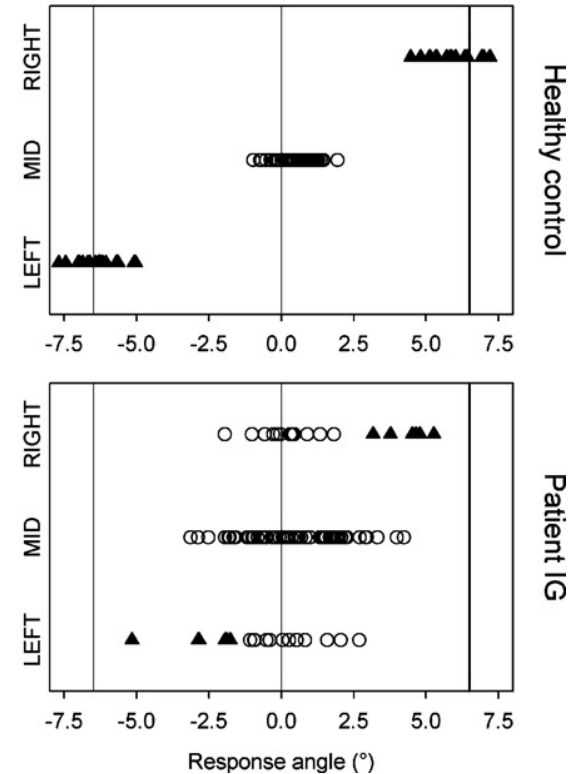

Fig. 2. Endpoints of reaching movements for one representative healthy control participant (top) and patient IG (bottom), for fixate left, fixate mid, and fixate right conditions. Data are separated on the ordinate according to target 2 location: left (jump left), mid (static trials) or right (jump right). The vertical lines indicate the lateral location of left, mid and right targets, and the heavy vertical line in each plot corresponds to the fixation location. For jump trials, unfilled circles indicate endpoints classed as uncorrected, and filled triangles indicate those classed as corrected.

\subsection{Processing of kinematic data}

Trials in which a saccadic eye movement was detected were discarded, though these trials were rare. Kinematic data from reaching movements were filtered by a dual pass through a Butterworth filter with a cut-off of $10 \mathrm{~Hz}$. Movement onset was determined using a velocity threshold of $100 \mathrm{~mm} \mathrm{~s}^{-1}$, and offset using a threshold of $50 \mathrm{~mm} \mathrm{~s}^{-1}$. The analysis of the spatial trajectory of the movement was performed by projecting the hand path onto the plane intersecting the start button and the three target locations, with its origin at the start button. A straight path from start button to the central target defined increasing depth displacement. Leftward lateral displacement was signed negatively, and rightward positively.

The analysis of online corrections in individual jump trials was based upon deviations of the hand path from the average spatial path of the hand on static trials, using a bandwidth based upon the movement variability of control participants. First, the spatial trajectories for all static trials were normalised to $1 \mathrm{~mm}$ increments along the depth axis. Second, for each participant, for each fixation condition, the average lateral coordinate and its standard deviation were calculated at each depth increment. Third, for each fixation condition, the average standard deviation was calculated across all control participants at each depth increment, and these were used to define standard cut-offs for all participants, including IG, for the purposes of classifying corrections in jump trials. Standard cut-offs were used so that the sensitivity of our analysis of corrections would be minimally influenced by individual differences in movement variability. At each depth increment, cut-offs were set at 2.81 average standard deviations either side of that participant's average hand path for that fixation condition. For each jump trial, in each time frame, the movement was classed as corrected if it fell beyond the corresponding cut-off in the direction of the jump, being otherwise classed as uncorrected. Each comparison thus approximates a one-tailed comparison at alpha $\sim 0.0025$, constraining type I error rate to 0.05 across the 20 jump trials per participant per fixation condition. The comparison made for the final frame of the movement defined the terminal correction status for each jump trial.

\section{Results}

Parametric comparisons of IG and controls were performed using the modified $t$-test of Crawford and Garthwaite (2002); $t$ values are reported for significant comparisons only.

\subsection{Reaching task: static trials}

In static trials, across fixation conditions, IG's movements were similar to controls' in duration (mean $430 \mathrm{~ms}$; control mean 456, SD 52.48) and peak speed (mean $2232 \mathrm{~mm} \mathrm{~s}^{-1}$; control mean 2038 ,
SD 260.38). Her signed endpoint error was within normal limits with mid fixation (mean $0.27^{\circ}$; control mean 0.05 , SD 0.21 ) and right fixation (mean $0.48^{\circ}$; control mean 0.09 , SD 0.35 ), and only marginally abnormal with left fixation (mean $0.89^{\circ}$; control mean 0.16, SD 0.36; $t=1.94$; two-tailed $p<0.1$ ). However, IG's bilateral optic ataxia was readily apparent in terms of her variable error (standard deviation of signed error), which was slightly inflated with mid fixation (mean $0.75^{\circ}$; control mean 0.50, SD 0.09; $t=2.67$; one-tailed $p<0.05$ ), and dramatically inflated with left fixation (mean $1.47^{\circ}$; control mean 0.60 , SD $0.09 ; t=9.26$; one-tailed $p<0.0005$ ) and right fixation (mean $1.64^{\circ}$; control mean 0.68 , SD 0.13 ; $t=7.07$; one-tailed $p<0.0005$ ), when the target was lateralised to extrafoveal vision. These patterns of misreaching can be appreciated by looking at the ranges of reaching endpoints for the mid target conditions in Fig. 2.

\subsection{Reaching task: jump trials}

IG was impaired in her ability to make trajectory corrections on jump trials, and this was most apparent in the lateral fixation conditions. With left fixation, her movements ended in a corrected position on only $21 \%$ of jump left (control median 95 , range $80-100$ ) and $22 \%$ of jump right trials (control median 100, range 100-100). With right fixation, IG's terminal correction rates were $35 \%$ for jump left (control median 100, range $80-100$ ) and 32\% for jump right trials (control median 100, range 75-100). With central fixation, IG produced higher terminal correction rates: $65 \%$ for jump left (control median 95, range 40-100) and 90\% for jump right trials (control median 95, range 55-100). However, this does not imply that her reactions were normal, even in this condition. First, the corrections that she made were of relatively small amplitude, as illustrated in Fig. 2. Second, the terminal correction status reflects the position of the hand at the end of the movement, but does not index the latency of any correction. A more informative picture is obtained by considering correction rates as a function of time since target jump.

Fig. 3 shows the development of correction rate over time (up to $350 \mathrm{~ms}$ ) in each fixation and jump condition for the control group 
Fixate left
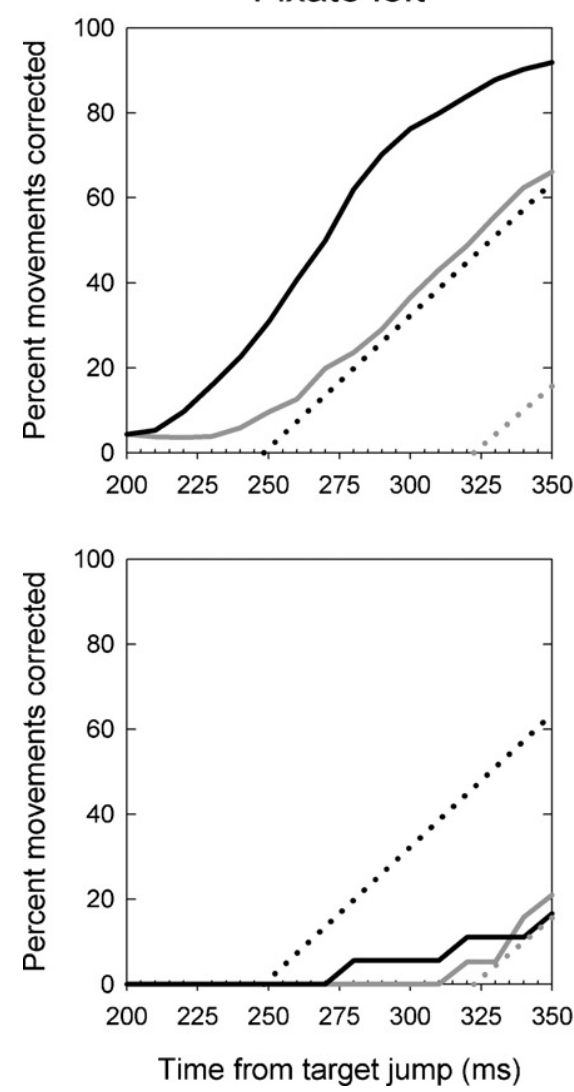

Fixate mid
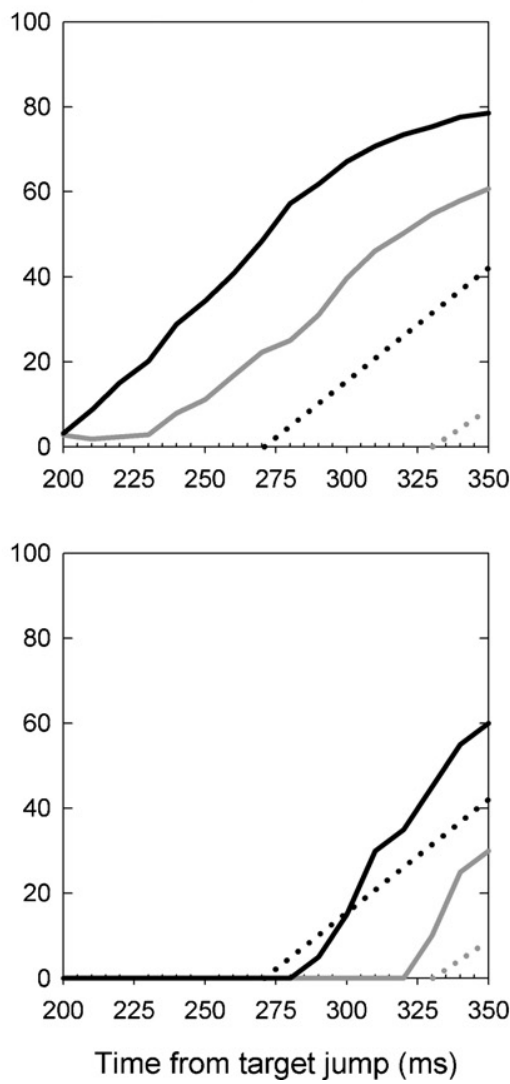

Fixate right
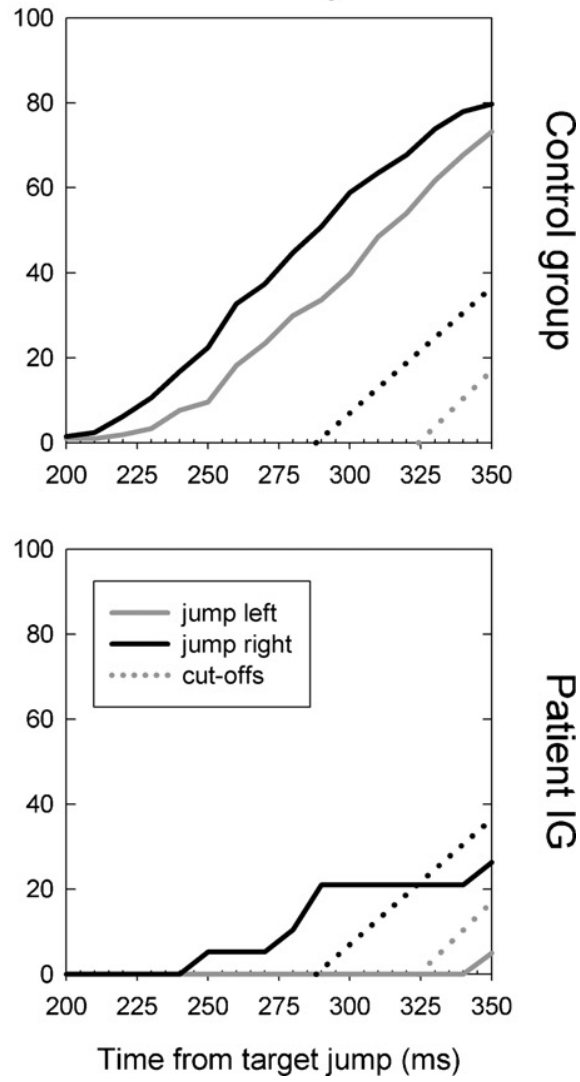

Fig. 3. Percentage movements corrected against time from target jump for the healthy control group (top) and patient IG (bottom), for fixate left, fixate mid, and fixate right conditions (see Section 2.6 for details). Solid lines represent observed correction rates, and dotted lines represent best fitting straight lines through the lower normal cut-off for corrections (one-tailed) (Crawford \& Garthwaite, 2002) against time. Black lines relate to jump right, and grey lines to jump left trials. Note that these profiles reflect the number of movements classified as corrected at each time, expressed as a proportion of the total number of movements ongoing at that time. These are therefore not cumulative rates of correction, but separate estimates of correction rate for each time. The plots do not extend beyond $350 \mathrm{~ms}$ because too few movements were represented beyond this time to allow reliable estimates of correction rate. Accordingly, the latest rate of correction plotted here (at $350 \mathrm{ms)} \mathrm{does} \mathrm{not} \mathrm{necessarily} \mathrm{correspond} \mathrm{to} \mathrm{the}$ terminal correction rates estimated from movement endpoints.

and for patient IG. In all conditions, IG's performance is at the lower end of the normal range, or is frankly abnormal. IG is most profoundly impaired in the conditions in which the target jumps from an extrafoveal to a peripheral location (fixate left, jump right; fixate right, jump left). It is also notable that she shows no benefit when the target jumps from extrafoveal vision to central vision (fixate left, jump left; fixate right, jump right), as compared with target jumps from a central to an extrafoveal location (fixate mid, jump left; fixate mid, jump right). This refutes the hypothesis that IG's correction deficit depends solely on the location towards which the correction is required, which would predict faster corrections towards central vision.

In a previous study of IG's online correction, the time-course of correction was inferred from the landing positions of movements of different durations, as recorded by a touchscreen (Pisella et al., 2000). The present trajectory-based method allows a more direct and detailed assessment, since correction status can be tested at every time point throughout the movement. However, along with several other methodological differences, ${ }^{1}$ the differ-

\footnotetext{
${ }^{1}$ The reaches in the present study were made in depth rather than vertically upward; the reach distance was more than twice as far ( $500 \mathrm{~mm}$ vs. $225 \mathrm{~mm}$ ); the target dots were much larger $\left(1.7^{\circ}\right.$ vs. $\left.0.5^{\circ}\right)$; the jump was of greater amplitude $(65 \mathrm{~mm}$ vs. $35 \mathrm{~mm})$ and visual angle $\left(8.8^{\circ}\right.$ vs. $\left.6.7^{\circ}\right)$, yet of smaller angular displacement with respect to the hand's start position $\left(7.58^{\circ}\right.$ vs. $\left.9.0^{\circ}\right)$; target jumps were more common ( $33 \%$ vs. $20 \%$ of trials); but the jump direction was less predictable; and central fixation rather than free vision was used.
}

ent approaches preclude a direct quantitative comparison of IG's performance between the two studies. Moreover, whereas Pisella et al. (2000) based their cut-offs for corrections on each participant's variability of reaching to static targets, we used standardised cut-offs based on the average control variability. We did this to prevent IG's correction rates being underestimated simply due to her higher baseline reaching variability (which would have yielded more conservative cut-offs). Our adoption of standardised cut-offs will have made our estimates of IG's correction rates, if anything, slightly more liberal than Pisella et al's, even though we used a more stringent statistical criterion (2.81 SD vs. 1.96 SD from the mean). Notwithstanding these differences, a consistent picture of IG's correction behaviour is painted by the two studies. Like Pisella et al., we found that almost none of IG's corrections emerged within $300 \mathrm{~ms}$ after the target jump, whilst the vast majority of control participants' corrections emerged within 200-300 ms. Overall, IG's online correction deficit seems to have changed very little in the intervening decade.

\subsection{Perceptual discrimination task}

All participants discriminated the direction of target jump with high accuracy and few false alarms on static trials (total errors for IG: 2; control range 0-6). Reaction times, trimmed for outliers ( $>2$ SD from the mean per participant), are displayed in Fig. 4, left panel, for IG and the control group. IG showed abnormally slow perceptual discrimination of target jumps to the most peripheral 

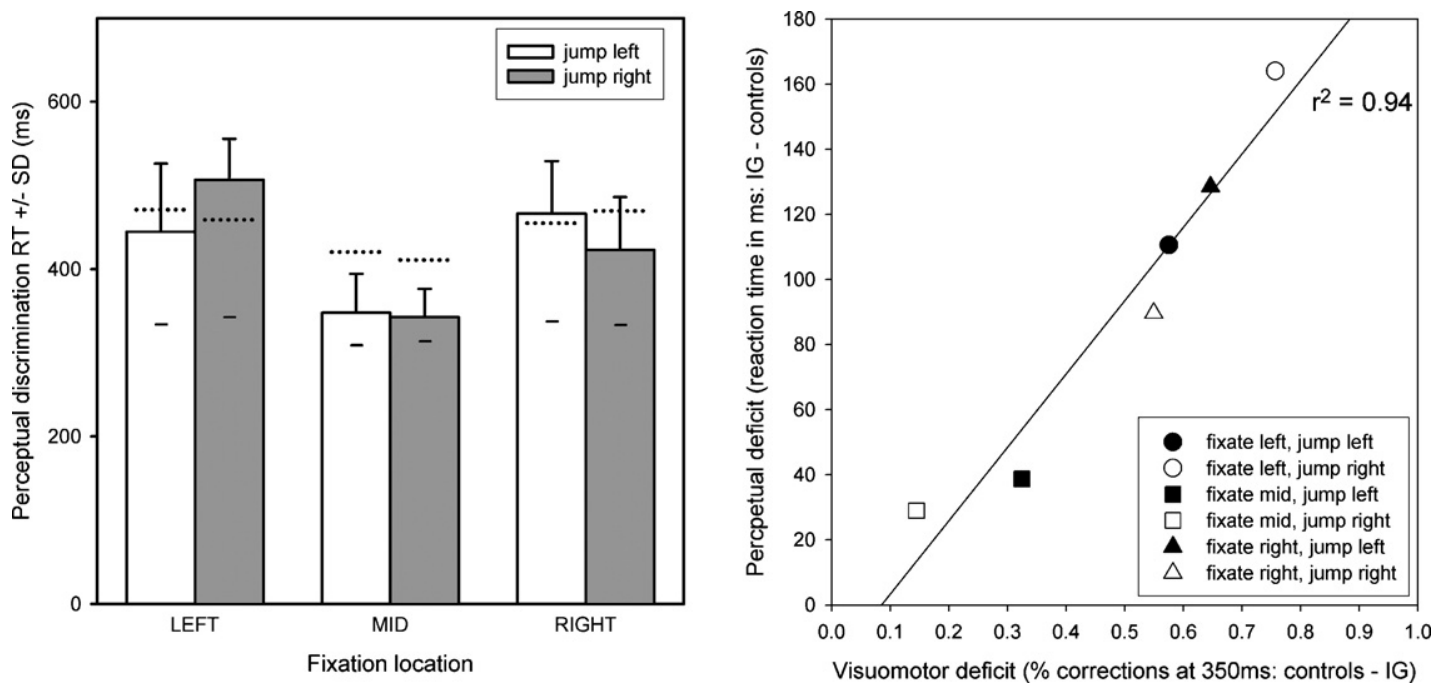

Fig. 4. The left panel shows mean perceptual discrimination RT $( \pm S D)$ of patient IG for each fixation and jump condition. The superimposed solid horizontal lines represent mean RT for the control group. The dotted horizontal lines represent the upper normal cut-offs (one-tailed) (Crawford \& Garthwaite, 2002). The right panel plots the best-fitting linear relationship between IG's perceptual and visuomotor deficits across fixation and jump conditions (see Section 3.3 for details).

locations (fixate left, jump right; fixate right, jump left), consistent with an attentional weakness for the ataxic fields, as noted by several authors (Blangero, Khan et al., 2010; Michel \& Henaff, 2004; Pisella et al., 2009; Striemer et al., 2007, 2009).

Crucially, IG's perceptual responses across the different fixation and target jump conditions closely mirrored her pattern of online correction in the reaching task. In order to capture this correspondence, we extracted a unitary measure of IG's deficit in each task, and examined the correlation of these across fixation and jump conditions. For the reaching task, the measure of deficit was the subtraction of IG's correction rate from the control mean at $350 \mathrm{~ms}$ (see Fig. 3). ${ }^{2}$ For the perceptual task, we used the subtraction of the control mean from IG's RT (see Fig. 4, left panel). Fig. 4, right panel, shows the linear correspondence between these measures across fixation and jump conditions $\left(r^{2}=0.94\right)$, indicating that IG's online correction deficit is strongly and directly related to her perceptual impairment.

\section{Discussion}

We confirmed an impairment of online correction of reaching in the bilateral optic ataxic patient IG (Gréa et al., 2002; Pisella et al., 2000). Consistent with the well-known dependence of optic ataxia on retinal eccentricity, this deficit was most severe for target jumps to more peripheral locations. However, we also observed slow perceptual discrimination of peripheral target jumps, supporting the idea that optic ataxia may involve an impaired ability to orient attention within ataxic visual fields (Blangero, Khan et al., 2010; Michel \& Henaff, 2004; Perenin \& Vighetto, 1988; Pisella et al., 2009; Striemer et al., 2007, 2009).

A key question is whether perceptual deficits in optic ataxia share a common basis with the visuomotor symptoms that define the condition, or whether they are independent consequences of dorsal stream damage. A previous examination of this issue judged in favour of functional independence, based upon divergent patterns of modulation of visuomotor and perceptual symptoms with retinal eccentricity in an ataxic field: accuracy of reaching declined with target eccentricity, but perceptual detection latencies, though

\footnotetext{
$2350^{\circ} \mathrm{ms}$ was chosen as the optimum time point by which to represent the patterns in Fig. 3 for the correlational analysis, since IG's correction rates had risen above floor, whilst control participants had not yet reached ceiling levels of correction.
}

slow, were relatively constant (Striemer et al., 2009). However, as the authors noted, reaching accuracy and detection time are very different behavioural measures, so may not provide an optimal basis for comparison. We attempted to match our perceptual and visuomotor tasks more closely, focusing on the speed of a discriminatory reaction to a target jump, and found a clear mirroring of performance across six different target conditions. It is hard to say whether this difference in outcome depends upon our choice of tasks, or simply upon our testing a different patient from Striemer et al. Either way, our results suggest that patient IG's perceptual deficits do not merely co-occur with her online correction deficit, but are functionally related. The fact that IG is also slow to make corrective saccades to displaced targets (Gaveau et al., 2008) suggests that common selection processes may support eye movements, hand movements, and perceptual discriminations.

It could be argued that the close correspondence between perception and action in the present study could nonetheless emerge from the interaction of functionally distinct deficits. A visuomotor deficit could account for IG's failure to make fast automatic corrections, but this would force her to rely on her perceptual awareness to initiate late voluntary corrections. If she also had an attentional deficit affecting her perception of target jumps, then this would determine the pattern of these late corrections. IG's attentional deficit would thus shape her correction behaviour, but only because she also has optic ataxia, which eliminates fast corrections. This hypothesis would predict that future optic ataxic patients should be found who show fully preserved attentional orienting in an affected visual field. In the absence of such patients, we prefer the more parsimonious idea that the perceptual and visuomotor symptoms of optic ataxia are commonly shaped by impaired attentional orienting in ataxic visual fields.

Our conclusion undermines the conventional clinical wisdom that optic ataxia is a pure visuomotor deficit, which occurs without corresponding perceptual problems. Rather, the data are consistent with an intimate linkage between visuospatial attention and visuomotor programming, which may depend upon shared pragmatic maps in and around the intra-parietal sulcus (Craighero \& Rizzolatti, 2005). Though tightly bound to motor control, these attentional functions may also gate access to conscious awareness, such that their damage impairs conscious visual perception. The perceptual consequences may be relatively subtle, mostly expressed as increased perceptual latencies, and easily overlooked in routine examination, in contrast with dramatic consequences for 
the fast control of action. Nonetheless, there is a growing body of converging evidence that perceptual counterparts to optic ataxia can be exposed by sufficiently stringent assessments, using difficult visual discriminations (Blangero, Khan et al., 2010; Michel \& Henaff, 2004; Pisella et al., 2009) or speeded responding (Striemer et al., 2007, 2009), in unilateral as well as bilateral cases.

In this regard, it is worth noting that optic ataxia commonly presents, acutely, alongside obvious attentional disturbances such as simultanagnosia or neglect-like lateralised biases. Post-acutely, the visuomotor symptoms may remain more apparent, because the fluent guidance of action is always time-pressured, whereas perceptual discriminations are usually made on softer deadlines. This idea raises the possibility that IG's impairment in our perceptual discrimination task could reflect a subtle subclinical form of the simultanagnosia that she had acutely, which might impair the rapid shifting of attention between the two target locations. This would predict that her online deficit would be ameliorated by the introduction of a temporal gap between offset of the first target and onset of the second; conversely, it should be exacerbated by temporally overlapping the two targets. This simple manipulation would be an interesting tweak to the present design, for future studies.

Our experimental design also tested the hypothesis that the online correction deficit in optic ataxia simply reflects an inability to rapidly program a movement towards a target in an ataxic field. This predicts that the online deficit should disappear, or at least be greatly ameliorated, when the target is jumped to a nonataxic part of the visual field. The prediction was definitively refuted by patient IG, who performed, if anything, more poorly for target jumps from extrafoveal to central vision than vice versa. The initial target location, as well as the jumped target location, is thus important in determining the online deficit. This could be explained in at least two ways. First, online correction requires the current hand position and the intended target location to be represented simultaneously. If optic ataxia involves impaired attention to extrafoveal locations, this may compromise the representation of ongoing extrafoveal reaches. Thus, if a foveal reach must be diverted to an extrafoveal location, current hand position may be well represented but the new target is not; conversely, if an extrafoveal reach must be diverted towards fixation, the new target may be well represented but the current hand position is not. In the one case, the visuomotor system knows where the hand is, but not where to go; in the other, it knows where to go to but not where from; in either case, the correction will fail. We may call this the 'positional' hypothesis.

An alternative possibility is that the key factor is neither the current hand position nor the new target position per se, but their spatial relationship, such that the deficit is determined by the direction of the required correction. This directional dependence could arise if the dorsal stream in each hemisphere subserves contralaterallydirected orienting behaviour (cf. Kinsbourne, 1970). According to this 'directional' hypothesis, optic ataxic patients would have impaired contralesionally directed corrections across the entire visual field. A bilateral patient such as IG would thus fail to make fast corrections in either direction, regardless of fixation position, as observed. A critical test of this idea would require a unilateral optic ataxic patient with field-dependent misreaching to be tested on our reaching task, allowing for the direction of jump to be dissociated from involvement of the ataxic field. The positional hypothesis predicts that such a patient would fail to correct when a target jumps from the ataxic field to the point of fixation, but not when it jumps from the non-ataxic field to fixation. The directional hypothesis predicts the opposite, as the former condition requires an ipsilesionally directed correction, so should be preserved, whilst the latter requires a contralesionally directed correction, so should be impaired. Moreover, if the online correction deficit is indeed related to impaired orienting of attention, as we suggest, then cor- responding patterns should be seen in a matched perceptual task.

A further point of interest is the quality of IG's reaches to static targets. The modulation of misreaching by eccentricity that is fundamental to optic ataxia was observed in terms of reach precision, though not accuracy. This is quite compatible with prior reports. In a previous study (Milner, Dijkerman, McIntosh, Rossetti, \& Pisella, 2003; Rossetti et al., 2005), IG showed a pronounced bias for a target at $15^{\circ}$ eccentricity, but no reliable directional bias for targets at $8^{\circ}$ (comparable to the $8.8^{\circ}$ lateralised static targets in the present study). Moreover, like the present study, these prior data show that reach precision is poor even in central vision, for IG and another bilateral optic ataxic patient (AT) (Milner et al., 2003; Rossetti et al., 2005). This residual imprecision in central vision might be attributable to at least two sources. First, modest increases in reach variability for central targets could arise from impaired online correction (Glover, 2003; Pisella et al., 2000). This would be consistent with a directional deficit of online correction, as proposed above, according to which bilateral optic ataxia should compromise online correction throughout the visual field. Second, these variable errors could be related to an optic ataxic 'hand effect', associated with proprioceptive mislocalisation of the reaching hand (Blangero et al., 2007), which would persist even in central vision. Our data thus confirm the common wisdom that optic ataxia is worse for extrafoveal targets, but also highlight the less widely recognised fact that foveal reaching is not unimpaired either, at least in bilateral cases. Future studies should investigate the nature of the reaching errors in central vision more specifically.

This study adds to a growing body of evidence for impaired orienting of attention in optic ataxia (Michel \& Henaff, 2004; Pisella et al., 2009; Striemer et al., 2007, 2009). Our data imply a functional relationship between the perceptual and visuomotor impairments, suggesting that dorsal stream visuomotor processing influences visual awareness. This conclusion may appear problematic for Milner and Goodale's perception-action model of visual processing, according to which the visuomotor functions of the dorsal stream are independent of visual perception (Goodale \& Milner, 1992; Milner \& Goodale, 2006). However, the challenge may be less stark than it would seem, since Milner and Goodale acknowledge that the dorsal stream plays important roles in attention (e.g. Corbetta \& Schulman, 2002), and that these attentional functions can influence perceptual report (e.g. Rees, 2007). Even so, the discovery of perceptual deficits in optic ataxia emphasises the need for a reappraisal of dorsal stream roles in perception (see Schenk \& McIntosh, 2010). Finally, this paper has focused on deficits of online correction, but perceptual counterparts may exist for other aspects of optic ataxia. For instance, optic ataxic hand effects may reflect proprioceptive mislocalisation; but the hand is perceptually mislocalised even when it is not acting (Blangero et al., 2007). Whether perceptual counterparts exist for all, or for only some of the features of optic ataxia, is a key issue for future research, and for our fuller understanding of dorsal stream function.

\section{Acknowledgements}

The authors are grateful to IG for her dedication and goodhumour. We are indebted to Alexandra Reichenbach for suggesting the use of standardised cut-offs. This work was made possible by a Travel Grant awarded to RDM by the Guarantors of Brain, a Study Visit Grant awarded to AM by the Experimental Psychology Society, and was supported by INSERM. AM was supported by a studentship from the UK Economic and Social Research Council.

\section{References}

Bálint, R. (1909). Seelenlähmung des “Schauens”, optische Ataxia, räumliche Störung der Aufmerksamkeit. Monatsschrift für Psychiatrie und Neurologie, 25, 51-81. 
Blangero, A., Gaveau, V., Luaute, J., Rode, G., Salemme, R., Guinard, M., et al. (2008). A hand and a field effect in on-line motor control in unilateral optic ataxia. Cortex, 44(5), 560-568.

Blangero, A., Khan, A. Z., Salemme, R., Deubel, H., Schneider, W. X., Rode, G., et al. (2010). Pre-saccadic perceptual facilitation can occur without covert orienting of attention. Cortex, 46, 1132-1137.

Blangero, A., Menz, M. M., McNamara, A., \& Binkofski, F. (2009). Parietal modules for reaching. Neuropsychologia, 47(6), 1500-1507.

Blangero, A., Ota, H., Delporte, P., Revol, P., Vindras, P., Rode, G., et al. (2007). Optic ataxia is not only 'optic': Impaired spatial integration of proprioceptive information. Neuroimage, 36(2), T61-T68.

Blangero, A., Ota, H., Rossetti, Y., Fujii, T., Ohtake, H., Tabuchi, M., et al. (2010). Systematic retinotopic reaching error vectors in unilateral optic ataxia. Cortex, 46(1), 77-93.

Corbetta, M., \& Schulman, G. L. (2002). Control of goal-directed and stimulusdriven attention in the brain. Nature Reviews Neuroscience, 3, 201215.

Craighero, L., \& Rizzolatti, G. (2005). The premotor theory of attention. In L. Itti, G. Rees, \& J. K. Tsotsos (Eds.), Neurobiology of attention (pp. 181-186). New York: Elsevier.

Crawford, J. R., \& Garthwaite, P. H. (2002). Investigation of the single case in neuropsychology: Confidence limits on the abnormality of test scores and test score differences. Neuropsychologia, 40, 1196-1208.

Garcin, R., Rondot, P., \& de Recondo, J. (1967). Optic ataxia localized in two left homonymous visual hemifields (clinical study with film presentation). Revue Neurologique (Paris), 116, 707-714.

Gaveau, V., Pélisson, D., Blangero, A., Urquizar, C., Prablanc, C., Vighetto, A., et al (2008). Saccade control and eye-hand coordination in optic ataxia. Neuropsychologia, 46(2), 475-486.

Glover, S. (2003). Optic ataxia as a deficit specific to the on-line control of actions. Neuroscience \& Biobehavioral Reviews, 27(5), 447-456.

Goodale, M. A., \& Milner, A. D. (1992). Separate visual pathways for perception and action. Trends in Neurosciences, 15, 20-25.

Gréa, H., Pisella, L., Rossetti, Y., Desmurget, M., Tilikete, C., Grafton, S., et al. (2002). A lesion of the posterior parietal cortex disrupts on-line adjustments during aiming movements. Neuropsychologia, 40(13), 2471-2480.

Himmelbach, M., Karnath, H. O., Perenin, M. T., Franz, V. H., \& Stockmeier, K. (2006). A general deficit of the 'automatic pilot' with posterior parietal cortex lesions? Neuropsychologia, 44(13), 2749-2756.

Jackson, S. R., Newport, R., Husain, M., Fowlie, J. E., O’Donoghue, M., \& Bajaj, N. (2009). There may be more to reaching than meets the eye: Re-thinking optic ataxia. Neuropsychologia, 47(6), 1397-1408.

Karnath, H. O., \& Perenin, M. T. (2005). Cortical control of visually guided reaching: Evidence from patients with optic ataxia. Cerebral Cortex, 15(10), 15611569.

Kinsbourne, M. (1970). A model for the mechanism of unilateral neglect. Transactions of the American Neurological Association, 95, 143-146.

McIntosh, R. D. (2010). Optic ataxia. In E. B. Goldstein (Ed.), The sage encyclopedia of perception (pp. 706-708).
Michel, F., \& Henaff, M. A. (2004). Seeing without the occipito-parietal cortex: Simultagnosia as a shrinkage of the attentional visual field. Behavioural Neurology, 15(1), 3-13.

Milner, A. D., Dijkerman, H. C., McIntosh, R. D., Rossetti, Y., \& Pisella, L. (2003). Delayed reaching and grasping in patients with optic ataxia. Progress in Brain Research, $142,225-242$.

Milner, A. D., \& Goodale, M. A. (2006). The visual brain in action (2nd ed.). Oxford: Oxford University Press.

Perenin, M.T., \& Vighetto, A. (1988). Optic ataxia - a specific disruption in visuomotor mechanisms. 1. Different aspects of the deficit in reaching for objects. Brain, 111 643-674.

Pisella, L., Binkofski, F., Lasek, K., Toni, I., \& Rossetti, Y. (2006). No double-dissociation between optic ataxia and visual agnosia: Multiple sub-streams for multiple visuo-manual integrations. Neuropsychologia, 44(13), 2734-2748.

Pisella, L., Grea, H., Tilikete, C., Vighetto, A., Desmurget, M., Rode, G., et al. (2000). An 'automatic pilot' for the hand in human posterior parietal cortex: Toward reinterpreting optic ataxia. Nature Neuroscience, 3(7), 729-736.

Pisella, L., Ota, H., Vighetto, A., \& Rossetti, Y. (2008). Optic ataxia and Balint's syndrome: Neuropsychological and neurophysiological prospects. Handbook of Clinical Neurology, 88(3), 393-415.

Pisella, L., Sergio, L., Blangero, A., Torchin, H., Vighetto, A., \& Rossetti, Y. (2009). Optic ataxia and the function of the dorsal stream: Contribution to perception and action. Neuropsychologia, 47(14), 3033-3044.

Pisella, L., Striemer, C., Blangero, A., Gaveau, V., Revol, P., Salemme, R., et al. (2007). Perceptual deficits in optic ataxia? In P. Haggard, Y. Rossetti, \& M. Kawato (Eds.), Attention and performance. XXI: Sensorimotor foundations of higher cognition (pp. 47-71). Oxford: Oxford University Press.

Prado, J., Clavagnier, S., Otzenberger, H., Scheiber, C., Kennedy, H., \& Perenin, M. T. (2005). Two cortical systems for reaching in central and peripheral vision. Neuron, 48, 849-858.

Rees, G. (2007). Neural correlates of the contents of visual awareness in humans. Philosophical Transactions of the Royal Society B, 362(1481), 877-886.

Rossetti, Y., Pisella, L., \& Vighetto, A. (2003). Optic ataxia revisited: Visually guided action versus immediate visuomotor control. Experimental Brain Research, 153(2), 171-179.

Rossetti, Y., Revol, P., McIntosh, R. D., Pisella, L., Rode, G., Danckert, J., et al. (2005). Visually guided reaching: Posterior parietal lesions cause a switch from visuomotor to cognitive control. Neuropsychologia, 42, 162-177.

Schenk, T., \& McIntosh, R. D. (2010). Do we have independent visual streams for perception and action? Cognitive Neuroscience, 1(1), 52-78.

Schindler, I., Rice, N., McIntosh, R. D., Rossetti, Y., \& Milner, A. D. (2004). Automatic avoidance of obstacles is a dorsal stream function: Evidence from optic ataxia. Nature Neuroscience, 7, 779-784.

Striemer, C., Blangero, A., Rossetti, Y., Boisson, D., Rode, G., Vighetto, A., et al. (2007). Deficits in peripheral visual attention in patients with optic ataxia. Neuroreport, 18(11), 1171-1175.

Striemer, C., Locklin, J., Blangero, A., Rossetti, Y., Pisella, L., \& Danckert, J. (2009). Attention for action? Examining the link between attention and visuomotor control deficits in a patient with optic ataxia. Neuropsychologia, 47(6), 1491-1499. 